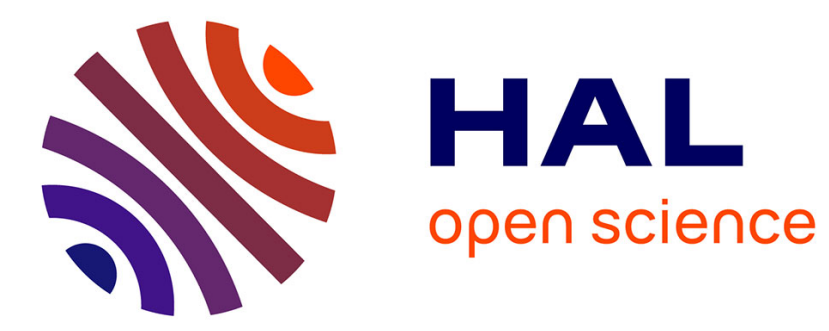

\title{
Effect of roughened strips on flood propagation: assessment on representative virtual cases and validation
}

\author{
A.R. Ghavasieh, C. Poulard, André Paquier
}

\section{To cite this version:}

A.R. Ghavasieh, C. Poulard, André Paquier. Effect of roughened strips on flood propagation: assessment on representative virtual cases and validation. Journal of Hydrology, 2006, 318 (1-4), p. 121 p. 137. 10.1016/j.jhydrol.2005.06.009 . hal-00451687

\section{HAL Id: hal-00451687 \\ https://hal.science/hal-00451687}

Submitted on 29 Jan 2010

HAL is a multi-disciplinary open access archive for the deposit and dissemination of scientific research documents, whether they are published or not. The documents may come from teaching and research institutions in France or abroad, or from public or private research centers.
L'archive ouverte pluridisciplinaire HAL, est destinée au dépôt et à la diffusion de documents scientifiques de niveau recherche, publiés ou non, émanant des établissements d'enseignement et de recherche français ou étrangers, des laboratoires publics ou privés. 
Author-produced version of the article published in Journal of Hydrology 2006, 318(1-4), 121-137

The original publication is available at http://www.sciencedirect.com/ doi :10.1016/j.jhydrol.2005.06.009 


\title{
Effect of roughened strips on flood propagation: assessment on representative virtual cases and validation
}

\author{
Ahmad-Reza Ghavasieh $^{\mathrm{a}}$, Christine Poulard ${ }^{\mathrm{b}}$, André Paquier ${ }^{\mathrm{b}}$ \\ a Assistant-professor in Power and Water Institute of Technology, Tehran-Iran. Email: \\ ghavasieh@pwit.ac.ir, fax: 0098217310425. \\ ${ }^{\mathrm{b}}$ Cemagref, Research Unit Hydrology-Hydraulics, 3bis quai Chauveau - CP 220, 69336 Lyon \\ Cedex 9, France. Email: poulard@lyon.cemagref.fr ; paquier@lyon.cemagref.fr \\ fax:: 0033478477875.
}

\begin{abstract}
The interaction between the main channel and floodplains is one of the interesting challenge topics in hydraulics of open channels. This knowledge can be useful for flood control purposes, if altering the land-uses. The aims of this paper are: (1) to investigate the effects of floodplain Roughened Strips for reducing and delaying flood peaks, (2) to compare the results of models (one- and two-dimensional hydraulic models) to find the limitations of application of the 1D model.

First, we assessed the effect of roughened strips on the propagation of flood hydrographs without/with roughened strips installed in four configurations of compound channels differing by width and slope. The regime always stayed subcritical. To quantify the effects of the roughened strips, proper indicators, such as relative attenuation and relative delay of peak, are proposed. For simple symmetrical arrangement of roughened strips, results of 1-D and 2-D models are quite similar: the effects are proportional to the roughened surface and the relative indicator values are almost constant with the flood return period. But in the case of more complex arrangements, it appeared that a 2D model should be used to obtain accurate results.

Finally, a test on river Hogneau was carried out. A simple interpolation method was devised to estimate a priori effects on flood mitigation of Roughened Strips implementation, using the results of simulation on the compound channels. It yielded indicators of the same order of magnitude than results of complete modelling.
\end{abstract}

Keywords: Roughened Strips, Compound Channels, Hydraulic Modelling, Flood Propagation.

\section{Introduction}

For two decades now, global solutions in a sustainable development plan are recommended for mitigating flood damages (Mays 1996).

In France, the Research Institute Cemagref promotes integrated basin management, and has focused its investigations on the methods of Dynamic Flood Control (Poulard and Oberlin 2002). DFC methods deal with measures such as dense vegetations, small retention structures, transverse levees, diversion canals or ditches for reducing the flow velocity or for delaying a part of flood volume. Small measures respectful of the ecosystems are preferable to huge structures such as dams and large reservoirs that unbalance the river dynamics and cut its continuity. It is also strongly stressed to integrate management at basin scale, in order to avoid solutions that reduce flooding at one point but will worsen the situation downstream.

Roughened Strips, noted hereafter "RS", are zones in the floodplain where roughness is enhanced by vegetation or stone arrangements. (Poulard and Oberlin, 2002) proposed them as one of the possible tools for Dynamic Flood Control. The purpose of this paper is to quantify this expected effect. To achieve this aim, design hydrographs were routed in channels with 
various geometrical configurations, and the results of $1 \mathrm{D} / 2 \mathrm{D}$ hydraulic models were compared.

The theoretical justification lies in the increased energy losses in a compound channel (Pang 1998, Yen 2002), because of lateral momentum transfer phenomena (Knight and Brown 2001, Myers and Lyness 2000). Energy consumption in a compound channel increases with floodplain roughness and depends on the water stages. A higher roughness decreases the flow over the floodplain and enhances the difference between main channel and floodplain velocities (Jayaratne and Tu et al. 1995).

Despite of intensive research activities on compound channels, some major aspects are still under investigation. Most efforts to study the effects of vegetal resistance have concentrated on steady-state regime and less is known about unsteady regime.

The results of Wolff and Burges (1994) about the influence of channel properties on routed hydrographs are very interesting for our purpose. They applied a one-dimensional hydraulic model to simulate the propagation of synthetic hydrographs in different compound channels. Their findings show that the amount of reduction in peak flow rates depended on the effective storage of the reach.

Papers dealing with the link between vegetation and effective roughness, including considerations about the variation of roughness with the water stage, are also valuable for our aims (Kouwen and Fati-Moghadam 2000), (Järvelä 2002). But in this paper, because of a simplified approach, the roughness coefficients $\mathrm{n}$ are assumed constant.

The most authoritative sources for $\mathrm{n}$ are the table in Chow (1959), the picture report of Barnes (1967) and the guide of USGS prepared by Arcement and Schneider (1989).

First, to quantify the effects of RS, in the "Channel configuration" paragraph, geometries of four virtual compound channels are determined through dimensional and sensitivity analyses, meeting geomorphologic constraints. Choice of input hydrographs and simulation tools is presented in the "Boundary conditions" and "Hydraulic models" paragraphs. Various arrangements are defined in the "Roughened strips scenarios" paragraph to find out the effects of symmetrical and asymmetrical roughened zones, length of strips and discontinued zones. The procedure of hydraulic simulations and quantification the effects by dimensionless indicators are described in the "Assessment procedure" paragraph. Then, results on the virtual compound channels are detailed and their extension to a real case is discussed.

\section{Channel configurations}

The geometrical parameters of a channel determine its storage capacity and conveyance. They are therefore important on peak attenuation and hydrograph deformation. Woltemade and Potter (1994) studied the effect of some parameters like valley width, slope and roughness in the Grant river (Wisconsin). They note that the influence of the parameters on flood peaks attenuation is considerable for events with a return period lower than 50 years, especially for fast rising floods.

\section{Channels parametrisation}

The number of parameters taken in consideration had to be limited due to the cost of simulations Generally, we should also consider other geometric parameters like the main channel section area.. So, dimensional and sensitivity analyses were carried out as preliminary work, to choose the most interesting parameters for establishing a set of representative and various channels. 
We considered a symmetrical compound channel as shown in Fig.1 for the simulations in this study. For these preliminary studies, roughness was assumed constant in the main channel $\left(n_{m c}\right)$ and in the floodplain $\left(n_{f p}\right)$.

We studied the sensitivity for each parameter, the other parameters being fixed, for two different propagated hydrographs. For the smallest hydrograph, the main channel overflowed just for the peak ; for the second one, the whole floodplain width was under water (Fig.2). factor.

The longitudinal slope, determinant for flow regime, appeared of course as an essential

The most important parameters of the cross-section were more difficult to establish. Just as an example, we present here briefly the effect of the floodplain width. Our tests show that the ratio of the floodplain width to the top width of main channel, $B / L$, and the lateral slope of floodplain $i_{2}$ are significant parameters for deformation of the propagated hydrograph. The influence of the slope of floodplain bank $i_{3}$ on the propagated hydrograph is less sensitive, especially for high values of $B / L$.

Two important factors for diffusion and convection of a hydrograph are wetted perimeter $P$ and wetted area $S$ of the channel section (Moussa 1996). The value of wetted perimeter is relevant for reducing the peak of propagated hydrograph whereas an increase of wetted area can increase the celerity of the peak.

Fig.3 illustrates the evolution of these factors with the water depth in the channels used for simulations of Fig.2.

In Fig.3.a, three phases can be distinguished and related to the water level rise: 1) in the main channel, 2) in the zone of slope $i_{2}$ and 3) in the zone of slope $i_{3}$. In the first phase, the wetted perimeter approaches rapidly to $50 \mathrm{~m}$ and stays almost invariable while $h_{b f}<2 \mathrm{~m}$. In the second phase, after overflowing till complete inundation of the floodplain, the wetted perimeter increases rapidly with the water depth. In the third phase, after complete inundation of the floodplain, $P$ remains almost constant like in first phase.

These three phases cannot be distinguished so well in Fig.3.b .

Thus, the efficiency of the wetted perimeter is considerable till the flood flows in the zone of slope $i_{2}$. The shoulder of a propagated hydrograph forms in this zone. Then, as soon as the peak overflows in the zone of slope $i_{3}$, it is the role of the wetted area $S$ which is more important than the wetted perimeter $P$. So the slope of rising limb of the propagated hydrograph will be steep (Fig.2.b).

\section{Channels dimensions}

The dimensions of the channels were selected in order to meet geomorphologic rules and to be coherent with the input hydrographs.

\section{Boundary conditions: choice of design hydrographs}

It was decided to choose a medium-size basin area, around $100 \mathrm{~km}^{2}$. In a previous study, a thorough hydrological analysis was carried out on a $125 \mathrm{~km}^{2}$ catchment, the Mediterranean river Mimente at Florac in southern France. We therefore decided to work with this hydrological data (Prudhomme et al., 1997).

To describe the hydrological regime of a river, Cemagref proposes the method QdF, based on the discharge-duration-frequency analysis that takes into account the temporal variability of floods. This method has been developed and completed during the last two decades ( Prudhomme et al., 1997; Javelle and Ouarda et al. 2002). The QdF analysis yields, 
for every return period, the value of discharge that is over-passed on average for a given set of durations. This information can be used to build a design hydrograph assumed to be representative of this return period: the Mono-Frequency Synthetic Hydrograph (MFSH) (Galéa and Prudhomme, 1994 ;Ghavasieh and Poulard 2003).

We therefore used as boundary conditions the MFSH of the Florac basin built for four return periods of 2, 10, 50 and 100 years (Fig.4). The aim was to study the effect of every RS scenarios on a wide range of return periods.

Table 1 presents the values of total volume for the design hydrographs used in this study.

The hydrographs of Florac basin have almost flash flood characteristics: high peaks compared to the flood volumes but we checked that in all our simulations the flow regime stayed always within the subcritical range.

Basin area is a factor closely-related to river cross-section. The channels used in this study were designed so as to have realistic dimensions for this area value.

\section{Choice of channels dimensions}

The concept of dominant discharge, which would control the form of the main channel, is a widespread subject of research (Doyle and Boyd et al. 1999). Theoretically, there should be a correlation between the specifications of a basin, such as its area, mean slope or its hydrological regime, and the dimensions of the cross section of river in the basin (Phillips 2002). In spite of these hypotheses and researches, finding a mathematical relationship is not always easy, because of the influence of various additional factors which make the correlation complicated.

However, measurements in some French catchments made it possible to estimate the parameters of the main channel according to the basin area (Revel and Lamouroux 2000). Channel A1 is defined respecting these data with a $B / L$ ratio of 5 and a mild $i_{2}$ slope. Indeed, a channel with high value of $B / L$ and a mild slope $i_{2}$ promotes the overflow in floodplain and deforms the input hydrograph considerably by delaying and smoothing the peak. This process will be certainly affected by the RS.

Overflows in floodplains usually happen for a 1.5 or 2 years flood (Castro and Jackson 2001). Based on this criterion, the main channel of A1 appears rather small. Thus the channel B1 with a larger main channel is defined.

We considered two bottom slopes for each channel, $0.05 \%$ and $0.2 \%$. The slopes strongly influence the value of bankfull discharge and so the deformation of the hydrographs.

According to above descriptions, Table 2 presents the symmetrical compound channel configurations: two different sections (A/B) with two bottom slopes $(1 / 2)$.

Comparing the bankfull and floodplain discharges $\left(Q_{b f}, Q_{f p}\right)$ confirms a wide range of characteristics which cover a large set of possible situations for hydrograph routing.

For the downstream limit condition, a rating curve was derived from the calculation of various discharges in steady states by each hydraulic model. This curve can not exactly express the discharge-stage relation in unsteady state. So there would be a perturbed distance close to the boundary. The observed perturbed zone was never longer than $500 \mathrm{~m}$ for our simulations. However, we fixed the observation section $1 \mathrm{~km}$ far from the downstream end of the channel reach. Therefore, the observation section in a $20 \mathrm{~km}$ channel was located at Pk19.

Hydraulic models 
For the simulations of RS in this paper, two hydraulic models were used: the onedimensional model Mage5 and the two-dimensional model RUBAR20. They have been developed in Cemagref and were validated during national and international projects (Paquier 1998).

The 1D model makes possible quick simulation of the effects of various symmetrical scenarios of RS installed in floodplain. In absence of sufficient field data, we make the assumption that the $2 \mathrm{D}$ model can be used as reference. The comparison between the results of similar 1D and 2D simulations permits to test the precision of the 1D model results and to investigate the limits of the 1D model compared to the 2D model.

These hydraulic models are briefly presented in the following paragraphs.

\section{$1 D$ model:}

Mage 5 is based on the semi-implicit scheme of Preissmann to discretise the system of Saint-Venant equations. At each time step, the iterative Newton-Raphson method is used to solve the system of equations obtained for the discharges and the water elevations in each cross section. The advantage of the implicit schemes is the high stability of calculations (Versteeg and Malalasekera 1995).

1D hydraulic models do not generally consider the lateral momentum transfer in the overflowing duration. Instead, for correcting the results in a compound channel, Mage5 uses the empirical Debord formula (Nicollet and Uan 1979). To take into account the additional energy losses at the interface between main channel and flood plain, this formula corrects the momentum coefficient $\beta$ and the energy gradient $I_{e}$ in the discretised equations in accordance with the water depth, the roughness and the conveyance of both the main channel and the floodplain. Appendix-2 describes briefly the Debord formula.

For the cases of compound channels using the input hydrographs, the sensitivity of results to the time and distance spacing was checked. Finally, convenient stability was obtained from the selected values of $60 \mathrm{~s}$ and $50 \mathrm{~m}$ respectively.

\section{D model:}

RUBAR20 solves the system of 2D shallow water equations, discretised for a grid made up of quadrilaterals and triangles using a finite volume method based on a conservative scheme of Van Leer type (Paquier 1995). A one-dimensional Riemann problem is solved in each time step to calculate input and output flows of every cell. Several tests confirm the adaptability of the numerical developed scheme to various situations of unsteady flows (Paquier 2001).

The stability of the calculations by the two dimensional scheme is ensured by the Courant-Friedrichs-Lewy condition (LeVeque 1990). The CFL condition limits the computation time-step value, which significantly increases the computing time.

Specification of domain geometry and grid design are the main tasks at the input stage for a two-dimensional model. One may await a more exact solution with a finer grid, which is obviously more expensive in term of computing time. There are no straightforward guidelines for optimizing the grid since it is problem dependent (Versteeg and Malalasekera 1995).

In the case of straight regular compound channels of Fig.1, instabilities on the water surface appeared in relation with boundary conditions. The amplitude of these oscillations became negligible with a 50 m longitudinal space step, 25 cells in each cross section to define the geometry accurately and a time step of $60 \mathrm{~s}$. 


\section{Roughened strips scenarios}

The channels and design hydrographs being chosen and integrated into a hydraulic model, it was thus possible to start the simulations.

The simulated channels were $20 \mathrm{~km}$ long and the observation point was located at the section of Pk19 (the upstream section was at Pk0 and the downstream section at Pk20). The RS are distributed in space between Pk13.5 and Pk17.5 (Fig.5). Thus, the observation section was located $1.5 \mathrm{~km}$ away from the last strip to avoid any local disturbance due to the RS (particularly a high cross velocity).

In a reference scenario S0, roughness of main channel and floodplain is homogeneous on all the sections. We considered $n_{m c}=0.033 \mathrm{sm}^{-1 / 3}$ (for clean straight natural stream) and $n_{f p}=0.067 \mathrm{sm}^{-1 / 3}$ (for floodway sluggish reach).

In addition to the reference scenario S0, four scenarios were defined, involving RS set in different patterns (Fig.5):

1. S0, the reference configuration; namely a floodplain without any RS, with a uniform floodplain Manning coefficient $\left(n_{f p}=0.067 \mathrm{sm}^{-1 / 3}\right)$,

2. S1, a transverse symmetrical strip of high roughness in floodplain $(1 \mathrm{~km}$ length, with the Manning coefficient of $n_{f p}=0.2 \mathrm{sm}^{-1 / 3}$ ),

3. S2, a strip similar with $\mathrm{S} 1$ but twice longer (length of $2 \mathrm{~km}$ ),

4. S3, two symmetrical successive strips similar to $\mathrm{S} 1,1 \mathrm{~km}$ apart from each other,

5. S4, asymmetrical configuration, with four alternated strips (Fig.5.d).

To model the presence of the RS in the floodplain, the floodplain roughness on their areas was increased to 0.2, which would correspond to a dense forest (Chow 1959).

With the scenario S1, the effect of the length two symmetrical zones of high roughness on the input hydrographs has been studied in the four channels, with both 1D and 2D models. The results of scenarios S1 and S2 were compared to check whether the effect is proportional to the length of RS.

The effect of the discontinuity in RS has been studied with the S3.

The scenario S4 was simulated only with the 2D model since the $1 \mathrm{D}$ model can not represent the asymmetric roughness. One expects that the asymmetrical scenario S4 causes an asymmetrical flow, which would make the main flow meander to avoid the zones of high roughness. These "meanders" were expected to amplify a priori the energy loss in the channels.

The results are discussed in a following section.

\section{Assessment procedure}

The following procedure is used to quantify the effects of the RS scenarios.

For each of the hydraulic models, four steps are carried out separately:

1. routing of the hydrographs determined in all the channels defined in Table 2, without any RS (S0), in Fig.4 to obtain the propagated hydrographs in Pk19 and the total volumes in the $20 \mathrm{~km}$ channels at each time step to have a reference,

2. phase 1 is repeated with each scenario of $\mathrm{RS}(\mathrm{S} 1, \mathrm{~S} 2, \mathrm{~S} 3, \mathrm{~S} 4)$,

3. the relative indicators (1) and (2), defined to quantify the effect of the RS on flood propagation, are calculated for each scenario S1 to S5 and compared,

4. the indicators obtained for the different return periods are compared within each scenario,

In parallel, a $5^{\text {th }}$ step consists in evaluating the relevance of the 1D hydraulic model, by comparing its results to the ones yielded by the 2D model, considered as the reference.

The indicators used to evaluate the influence of different RS scenarios are relative attenuation and relative delay of peak, respectively $d q_{r}$ and $d c_{r}$. They are calculated at Pk19 by: 
where:

$$
d q_{r} \%=\left(\frac{Q-Q_{w}}{Q}\right), d c_{r} \%=\left(\frac{\bar{c}-\bar{c}_{w}}{\bar{c}}\right)
$$

$Q$ is the peak discharge without $\mathrm{RS}, Q_{w}$ is the peak discharge with $\mathrm{RS}, \bar{c}$ is the mean celerity without RS (for the scenario S0) and $\bar{c}_{w}$ is the mean celerity with RS.

The third one is the percentage of extra water volume in the reach due to the presence of $\mathrm{RS}, d \operatorname{Vol}_{r}(t)$ to be calculated by:

where:

$$
d \operatorname{Vol} r(t) \%=\frac{\operatorname{Vol} l_{w}(t)-\operatorname{Vol}(t)}{\operatorname{Vol}_{t o t}}
$$

$\operatorname{Vol}_{w}(t)$ is the volume stored in the channel with RS at the moment $t$ (one of the scenarios

$\mathrm{S} 1$ to $\mathrm{S} 5), \operatorname{Vol}(t)$ is the volume stored in the channel without RS at the moment $t$ (Scenario S0) and $V o l_{\text {tot }}$ is the total volume of the input hydrograph.

\section{Results of simulations and discussion}

\section{Delay and decrease of peak}

Fig.6 illustrates the effects of the scenario S1 revealed by the relative attenuation and the relative delay in different channels obtained by the $1 \mathrm{D}$ model. The variations of $d q_{r}$ and $d c_{r}$ values with the return period, in Fig.6, are almost negligible specially for the channels A1, A2 and B2. For interpreting the results, it should be noted here that:

- on the one hand, the RS consists in an increase in the roughness, which increases the energy losses and thus delays the flood peak. While the floodplain is not completely filled, the increase in roughness raises the water free surface which consequently increases the wetted perimeter, while the wetted surface increases more slowly, and so the flow is slowed down. Beyond one specified peak discharge, the floodplain is completely inundated and the wetted perimeter does not increase much with the water stage (Fig.3.a).

- on the other hand, a hydrograph with a higher peak discharge has a higher mean celerity in a channel which tends to decrease the diffusion effect (Moussa 1996).

The floodplain in the channels $\mathrm{A} 1$ and $\mathrm{A} 2$ is fully inundated for all the input hydrographs peaks of Fig.4. Conversely, it is never completely inundated for channel B2. For channel $\mathrm{B} 1$, it depends on the return period: the floodplain is partially inundated by $\mathrm{T} 2$ and T10 but it is entirely inundated for T50 and T100 ( $Q_{f p}$ in Table 2$)$. That is why there is a rupture in trends of the indicators obtained for the channel B1 between T10 and T50.

The most significant parameter values are obtained for the channel A1, which has a mild bottom slope and the smallest bankfull discharge (Table 2). Indeed, the effects of RS in the mild slope channels are more significant than in the other channels. In these cases, the influence of the geometry can be observed too. Conversely, in the steep slope channels, the effects of RS are not very significant, and independent from the geometry (the results obtained for $\mathrm{A} 2$ and $\mathrm{B} 2$ are close).

Tables 3-4 provide the indicator values (average of results for the four return periods) for various scenarios obtained by the $1 \mathrm{D}$ and 2D models respectively. 
The RS for scenario S2 are twice longer than for scenario S1. The results obtained by the hydraulic models confirm that the effects of S2 are in all cases a bit less than the double of S1 (Tables 3-4).

The effect of scenario S4, obtained by the 2D model, is in general higher than S1 but less important than S2. It means that the meandering effect provoked by the pattern of RS in S4 is not considerable. Furthermore, the effects of the asymmetric configuration of RS in the scenario S4 are less than the effects of the symmetric RS scenario S3.

\section{Comparison of 1D-2D models}

The indicator values obtained by the 1D model are slightly higher than the values obtained by the 2D model. So, the results of the RS simulations with the $1 \mathrm{D}$ model are overestimated comparing to that given by the $2 \mathrm{D}$ model. However, quantitatively the difference between the results is not very important and their tendencies are often alike.

The total RS length of the scenario S3 is the same as S2. The indicator values for S2 and S3 are close, but the tendency of the results obtained by the two models are different: for the scenario $\mathrm{S} 3$, the $d q_{r}$ values obtained by the 2D model conversely with the 1D model, are more than the values obtained for $\mathrm{S} 2$.

Indeed, the difference between the scenarios S2 and S3 is negligible by the 1D model, while the 2D model is able to simulate the effects of successive convergence and divergence of flow made by the scenario S3. Effectively, this can increase the head losses caused by S3 comparing with S2. With proper roughness calibration, a 1D-model can therefore be acceptable to estimated water levels in symmetrical cases, but it must be stressed that if problems of sedimentation are feared due to the presence of RS (erosion/sedimentation), only the $2 \mathrm{D}$ models will yield the velocity fields needed to make a diagnostic (see next paragraph).

\section{Velocity}

The presence of RS in the floodplain reduce the velocity in this zone, and one may guess a velocity acceleration in the main channel specially on the symmetrical axis. But the results of the 2D model show a reduction of velocity in all the cells even in the main channel. The results for the velocity reduction on the symmetrical axis are given in Fig.8. The maximum reduction of velocity for $\mathrm{S} 1$ is calculated at the $\mathrm{Pk16.5}$, just upstream from the RS.

Fig. 8 illustrates the increase of velocity reduction with the return period in all channels. It is more important for the channels A1 and A2. However, it remains lower than $6 \%$ in all the tested cases.

\section{Volume}

The increased storage caused in the reach by the RS occurs obviously throughout overflowing. Thus, the curves of Fig.7.a start to rise as soon as the flow in floodplain reaches the RS. The maximum values are reached when the peaks of the hydrographs arrive at the RS and then they decrease with the flow. Fig.7.b presents the maximum values of the indicator $d V_{o l}(t)$ obtained by the 1D model for the four channels.

Comparing the results in Fig.7.b reveals that the indicator values:

- vary conversely with the bankfull discharge for the first hydrograph T2. It means that a channel which has a lower bankfull discharge causes a higher overstocking (Table1),

- decrease slightly with the return period while the floodplain is totally inundated,

- increase with the return period while the floodplain is not completely filled,

- seem to converge towards the same value in the channels that have identical slopes. 
The volume indicator values obtained for S2 are approximately twice higher than the values obtained for S1 in Fig.7.

\section{Effects further downstream}

The observation section in the simulations is chosen at $\mathrm{Pk} 19$, just downstream of the RS. It is interesting to know the variation of effects of the RS also further from this point. Thus, the channels were extended up to $50 \mathrm{~km}$ and the propagated hydrographs checked out in Pk29, Pk39 and Pk49 for the scenario S2 of RS.

Fig.9 presents the results for two hydrographs, T10 and T100. The results show that the delays of propagated hydrograph peaks increase slightly but the attenuations of peaks (without/with the RS) decrease rapidly downstream.-

\section{Case of Hogneau}

The results obtained on virtual cases showed that RS could be effective on flood mitigation, and gave order of magnitudes for several configurations. Tests on a real case were decoded to:

- $\quad$ test the applicability of the methods in a real context, with a non-homogeneous geometry ;

- check whether the order of magnitude of the effects in a real case with comparable parameters could be deduced a priori from the results of the set of simulations in various virtual channels (A1, A2, B1 and B2)..

Hogneau is a river located in Northern France. Its spring is in France, but the river flows into Belgium and then back to France. Its total catchment area is $240 \mathrm{~km}^{2}$.

Flood problems are frequent, especially in the downstream part, between two villages: Crespin and Thivencelle, in Valenciennes region (Fig.10.a). We therefore focused on the last $5180 \mathrm{~m}$ of the river. It is actually almost entirely channelized with an average slope of $0.08 \%$ (Fig.10.b). In this reach, since the Middle Ages, dikes were built to protect agricultural land from floods. Of course, they were breached many times, and systematically repaired and reinforced. The last event occurred in February 2002, when a major breach caused inundations in agricultural lands and in some isolated houses; Thivencelles village was threatened till the dike could be repaired.

This event led the local authority to undertake studies to lessen the flood risk. They asked several solutions to be tested. One of them is to use the agricultural terrains on the right side of the river, situated in vicinity of the $A 2$ highway, as retarding basins or expansion zone by increasing their roughness and promoting overflows in them (Fig.10.a). The left side of the river is not suitable to use as expansion zone because of an important regional road parallel to the river.

We tested the proposed scenarios, as limited by topography and land-use constraints.

So for this evaluation, regarding the practical and natural field restraints, the following scenarios are considered:

- H0: current situation of the river; the hydraulic models for this scenario can be calibrated with the existing data;

- H1: the right embankment of the river is shifted till $150 \mathrm{~m}$ to have an expanded floodplain. This is possible during $1900 \mathrm{~m}$ length $(750 \mathrm{~m}$ before and $1150 \mathrm{~m}$ after the A2 highway (Fig. 10.a), $\left.\left(n_{f p}=0.067\right)\right)$;

- $\mathrm{H} 2$ : the expanded zone is assigned a Manning coefficient of $0.2\left(n_{f p}=0.2\right)$. 
Change from scenario $\mathrm{H} 0$ to $\mathrm{H} 1$ represents floodplain enlargement, and from $\mathrm{H} 1$ to $\mathrm{H} 2$ it corresponds to the implementation of a Roughened Strip.

However this proposal has two drawbacks: the floodplain extension is rather limited, and the design hydrograph, with a 100 years return period, is too large. Indeed, the previous tests show that the RS have the best effectiveness when the flow is just inundating the floodplain, not for the major floods.

\section{Hydraulic models calibration}

We obtained the geometry of the reach from the local authority, "Communauté d'Agglomération Valenciennes Métropole" We checked the nature of the banks during field visits, and estimated a priori roughness coefficients, for each sub-reach, one for the river bed and one coarser for the river embankments. The reach was divided into six sub-reaches.

Two sets of data were available for the calibration process:

- $\quad$ a discharge-level curve from a gauging station located on the reach ;

- $\quad$ results of two campaigns of water levels measurements during the 2002 flood, which yielded water lines for two different discharges.

These data made it possible to adjust the initial roughness coefficients for both models respectively. The levels recorded for the lowest discharge were used to fix the bed river roughness coefficients and the level corresponding to the higher discharge helped finding the river banks coefficients.

The Manning coefficients found in this way for Hogneau range from 0.02 (river bed) to 0.1 (river banks). They are not exactly the same for two models. The coefficients values found by the $2 \mathrm{D}$ model are somewhat higher than the coefficients calibrated in the $1 \mathrm{D}$ model. It is not surprising, because of the different schemes used by the models for discretising and solving the equations.

\section{Results of simulations}

The flood hydrograph recorded in February 2002 was routed by the models through Hogneau with the scenarios $\mathrm{H} 0, \mathrm{H} 1$ and $\mathrm{H} 2$ as defined previously. The results for different scenarios calculated by the 1D model at Thivencelle are compared in Fig.11. The indicators computed values are given in Table 5 and 6 . Comparing $\mathrm{H} 0$ with $\mathrm{H} 1$ downstream hydrographs confirms the noticeable effect of expanded floodplain (especially on flood peak delay). But increasing the floodplain roughness by the scenario $\mathrm{H} 2$ seems to be not very significant.

The relative attenuation indicator, $d q_{r}$, confirms that the floodplain extension is not sufficient to achieve the requested flood peak reduction at the requested section, Thivencelle. On the other hand, the relative delay values, $d c_{r}$, are sufficiently significant to be useful for a flood warning system at Thivencelle.

The results obtained for Hogneau by the two hydraulic models are similar. It proves the satisfactory calibration of the models on this field case.

\section{Forecasting the effects}

At this point, there is an interesting question: could one estimate the effects of $R S$ method in the Hogneau case simply using the obtained results of A1, A2, B1 or B2 channel?

Just for a priori estimation, it is possible to use the results of the simulations with the best "conformity" with the case. The following parameters should be comparable between a channel and a real case:

- slope; it is the source of energy and appears directly in the Saint-Venant equations,

- $\quad \frac{B}{L}$ ratio; it reveals the floodplain storage capacity of a reach, 
- roughness of main channel and floodplain; they determine the slope of energy line,

- $\frac{Q_{b f}}{Q}$; where $Q_{b f}$ is the bank full discharge and $\mathrm{Q}$ is the flood peak. This parameter reveals the relative capacity of a main channel to convey the flood.

Hogneau river has a mean longitudinal slope of $0.08 \%$ and the $\frac{Q_{b f}}{Q}$ ratio for the February 2002 flood is $8 \%$. The nearest conditions among the simulated channel configurations are the channels A1 with T2 hydrograph and B1 with T100 hydrograph. The slope of both channels is $0.05 \%$ and the $\frac{Q_{b f}}{Q}$ ratio is $7 \%$ and $8 \%$ respectively. The $\frac{B}{L}$ ratio for both A1 and B1 channels is 5 which is less than 8 for the expanded floodplain in Hogneau.

$\mathrm{S} 2$ is the scenario closest to $\mathrm{H} 2$ in the Hogneau real case.

So, to estimate the effects of roughened floodplain in the real case, one can refer to the results of S2 of the channels A1 and B1 with T2 and T100 respectively. In Table 6 the calculated results for the channels and the real case are compared. It should be mentioned here that the reference scenario for the virtual channels is S0 but the reference for Hogneau is H1. The mean slope of Hogneau is steeper than the channels slope, and so the floodplain storage capacity in Hogneau is less than in the channels. A highway dike present in Hogneau floodplain interferes with the effects of roughened floodplain. Therefore, roughening method in the case study is expected to be less efficient than in the compound channels.

In spite of existence of the obstacle A2 highway in the real case and the physical characteristics differences between the real case and channels, the estimated values are not far from the calculated results.

\section{Conclusions}

Various channel configurations with four different input hydrographs were used to study the roughened strips effects. To limit the number of parameters of the problem, some assumptions about channel geometries, roughness coefficient and input hydrographs were applied. Dimensionless indicators were designed to provide quantified diagnostic of the efficiency. The results of this study are useful as a first assessment of floodplain roughening effects. In addition to the virtual cases in this paper, some supplementary simulations maybe needed with other channel cross sections or boundary conditions. For example, the efficiency of roughened strips on more voluminous input hydrographs may be less than the sharp peak hydrographs considered here.

The results of the simulations of the RS commented in this paper indicate that:

- for the configuration tested for roughened strips of S1, the relative attenuation and the relative delay of flood peak vary from $0.3 \%$ to $2.1 \%$ and from $2.4 \%$ to $5.6 \%$ respectively for different channels (Fig.6). The effect of roughened strips of S1 on relative stored volume in the channel reach can be up to $0.65 \%$ (Fig.7.b).

- the effects are approximately twice more important for the strips twice longer. Indeed, the indicator values are proportional to the surface of the RS.

- comparing the results of channels (A1-A2 and B1-B2), the RS are less effective in steeper channels (A2 and B2). Indicators computed for two steep channels with different cross-sections but the same longitudinal slope, A2 and B2, were very close. It means that in the case of steep channels, the effects are more correlated to this slope than to the cross section geometry. 
- the relative indicator values are almost constant with the return period in absence of geometrical discontinuity in floodplain for different flood levels (case of the channels $\mathrm{A} 1, \mathrm{~A} 2$ and $\mathrm{B} 2$ ).

- the storage of additional volume in a reach depends on the longitudinal slope of the channel and its bankful discharge.

- for a given hydrograph, the attenuation of peak (without/with the RS) decreases rapidly downstream far from the roughened zone. The peak delay values does not decrease with distance (Fig.9).

- comparing to 2-D model, the 1-D model generally slightly overestimates the effects of RS. Yet, for a case in which field data are convenient for the model calibration, 1D model seems enough to test the RS effects in symmetric configurations.

Re-allowing inundation in selected stretches of floodplain and using land-use modifications such as Roughened Strips are interesting for flood mitigation, but mainly for moderate floods. Sufficient space must be available, otherwise the effect is not significant, and this space must be relatively close to the area which needs protection: it was shown that although delay persists, the mitigation effect fades with distance.

In the case study, Hogneau, the consequence of floodplain enlargement in a limited stretch on the right side of the river is significant on downstream flood peak delay. Roughening the expanded zone is useful for minor floods but its effect is not very significant on a 100-year return period flood. This proves that, prior to any costly study to investigate the efficiency of $\mathrm{RD}$, it is interesting to have some orders of magnitude of expected effects. Therefore, the method proposed to estimate a priori the effects of RS on a real case using only the indicators calculated for a set virtual channels is very promising, to be used at feasibility study stage. It requires close enough physical characteristics, so to increase the range of validity of the method, more channel configurations should be tested in the future.

Finally, it must be stressed that to compare a strategy using these tools with a strategy of dikes or dams in an objective way, the environmental effects should be taken into account too; which remains up to now a difficult task.

\section{Acknowledgment}

The authors gratefully acknowledge the comments and discussions by MM. B. Gay and R. Perkins, Professors of Claude Bernard Lyon1 university, J.B. Faure and B. Chastan, researchers in Cemagref. The data obtained on the Hogneau river from the local authority "Communauté d'Agglomération Valenciennes Métropole" allowed us to present an analysis on a real case. 


\section{Notation}

Italic characters: symbols used

Normal characters: abbreviations used

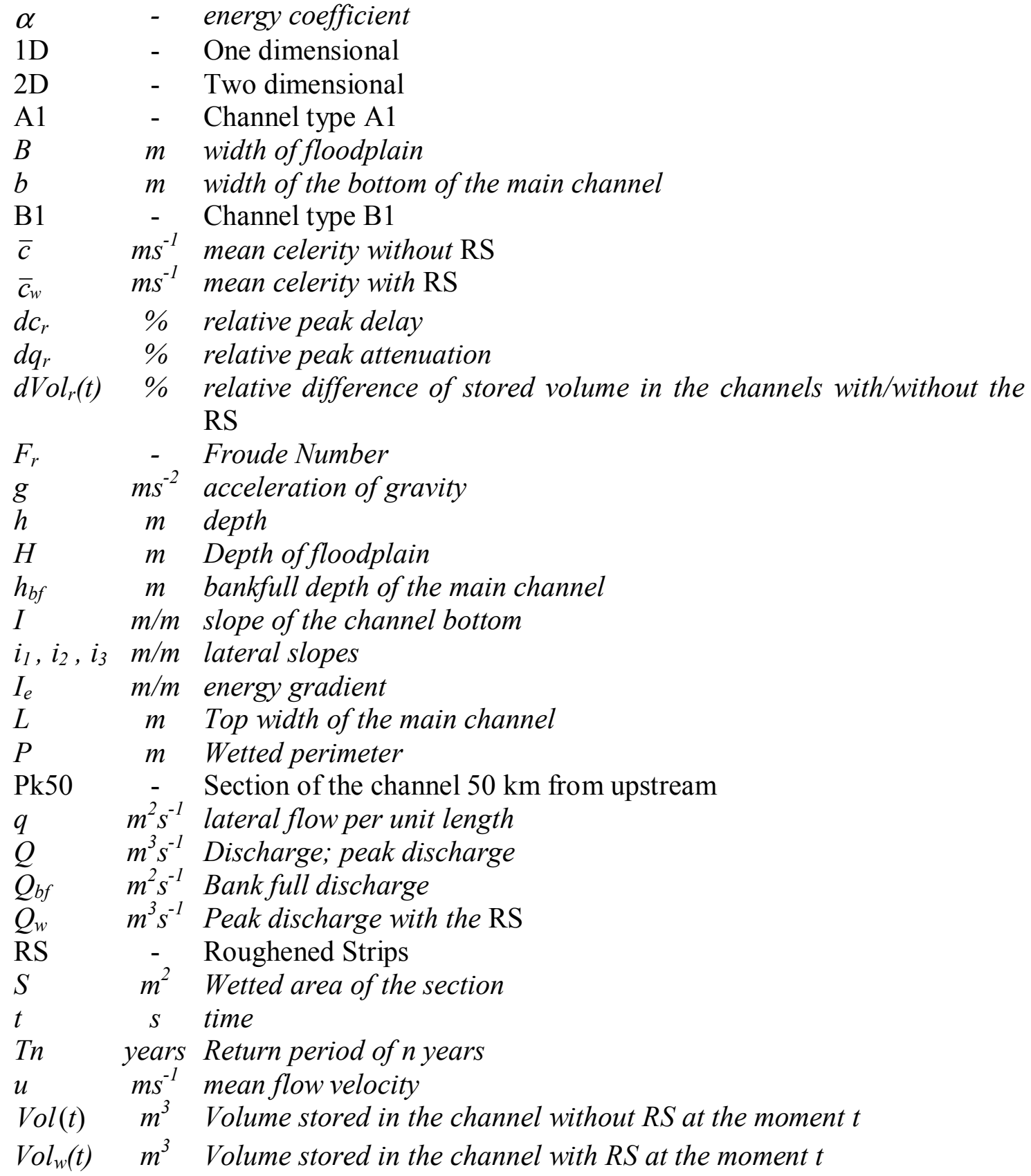

\section{Subscripts}

$$
\begin{aligned}
* & =\text { dimensionless } \\
\mathrm{bf} & =\text { bankfull } \\
\mathrm{e} & =\text { energy } \\
\mathrm{fp} & =\text { floodplain } \\
\mathrm{mc} & =\text { main channel } \\
\mathrm{r} & =\text { reference } \\
\mathrm{tot} & =\text { total }
\end{aligned}
$$




\section{Tables}

Table 1. Volumes of the input hydrographs $\left(\right.$ Vol $\left._{t o t}\right)$

\begin{tabular}{|l|c|c|c|c|}
\hline Hydrograph & T2 & T10 & T50 & T100 \\
\hline Volume $\left(\mathrm{Mm}^{3}\right)$ & 20.108 & 34.483 & 54.394 & 65.702 \\
\hline
\end{tabular}

Table2. Configurations of the channels

\begin{tabular}{|c|c|c|c|c|c|c|c|c|}
\hline Canal & $\mathbf{b}(\mathbf{m})$ & $\mathbf{L} \mathbf{( m )}$ & $\mathbf{h}_{\text {bf }} \mathbf{( m )}$ & $\mathbf{B}(\mathbf{m})$ & $\mathbf{H}(\mathbf{m})$ & $\mathbf{I}^{\mathrm{a}}$ & $\left.\mathbf{Q}_{\mathbf{b f}} \mathbf{( m}^{\mathbf{3}} / \mathbf{s}\right)^{\mathrm{b}}$ & $\mathbf{Q}_{\mathbf{f p}}{ }^{\mathrm{c}}$ \\
\hline $\mathbf{A 1}$ & 18 & 30 & 1.0 & 150 & 2.0 & 0.0005 & 13.8 & 58 \\
\hline $\mathbf{A 2}$ & 18 & 30 & 1.0 & 150 & 2.0 & 0.0020 & 27.6 & 115 \\
\hline B1 & 40 & 70 & 1.5 & 350 & 3.8 & 0.0005 & 61.7 & 435 \\
\hline B2 & 40 & 70 & 1.5 & 350 & 3.8 & 0.0020 & 123.3 & 870 \\
\hline
\end{tabular}

Symbols are defined in Fig. 1 .

a. $I$ is the slope of channel bottom.

b. $Q_{b f}$ indicates the bankfull discharge of the main channel in steady flow.

c. $Q_{f p}$ is the minimum discharge needed for inundating the width B (floodplain) in steady flow.

Table 3. Average indicator values obtained by $1 \mathrm{D}$ model

\begin{tabular}{|l|c|c|c|c|c|c|c|c|}
\hline \multirow{2}{*}{ scenario } & \multicolumn{4}{|c|}{$d q_{r} \%$} & \multicolumn{4}{c|}{$d c_{r} \%$} \\
\cline { 2 - 9 } & $\mathbf{A 1}$ & $\mathbf{A 2}$ & $\mathbf{B 1}$ & $\mathbf{B 2}$ & $\mathbf{A 1}$ & $\mathbf{A 2}$ & $\mathbf{B 1}$ & $\mathbf{B 2}$ \\
\hline S1 & 2.05 & 0.47 & 1.32 & 0.37 & 5.40 & 3.05 & 3.55 & 2.85 \\
\hline S2 & 3.82 & 0.85 & 2.55 & 0.78 & 9.30 & 5.85 & 6.63 & 5.20 \\
\hline S3 & 3.70 & 0.80 & 2.45 & 0.77 & 9.30 & 6.37 & 6.77 & 5.30 \\
\hline
\end{tabular}

Table 4. Average indicator values obtained by 2D model

\begin{tabular}{|l|c|c|c|c|c|c|c|c|}
\hline \multirow{2}{*}{ scenario } & \multicolumn{4}{|c|}{$d q_{r} \%$} & \multicolumn{4}{c|}{$d c_{r} \%$} \\
\cline { 2 - 9 } & $\mathbf{A 1}$ & $\mathbf{A 2}$ & $\mathbf{B 1}$ & $\mathbf{B 2}$ & $\mathbf{A 1}$ & $\mathbf{A 2}$ & $\mathbf{B 1}$ & $\mathbf{B 2}$ \\
\hline S1 & 1.65 & 0.37 & 0.57 & 0.10 & 5.05 & 2.52 & 3.40 & 2.72 \\
\hline S2 & 2.87 & 0.67 & 1.17 & 0.22 & 8.20 & 4.60 & 5.25 & 4.50 \\
\hline S3 & 3.02 & 0.68 & 1.22 & 0.25 & 8.77 & 5.10 & 4.82 & 4.50 \\
\hline S4 & 2.15 & 0.45 & 1.07 & 0.20 & 7.20 & 3.80 & 4.22 & 3.97 \\
\hline
\end{tabular}

Table 5. Indicators values at Thivencelle section (Hogneau) for flood plain extension

\begin{tabular}{|l|r|r|r|r|r|r|}
\hline \multirow{2}{*}{ scenario } & \multicolumn{3}{|c|}{ 1D Model } & \multicolumn{3}{|c|}{ 2D Model } \\
\cline { 2 - 7 } & $\mathrm{dq}_{\mathrm{r}} \%$ & $\mathrm{dc}_{\mathrm{r}} \%$ & $\mathrm{dVol}_{\text {rmax }^{*}}$ & $\mathrm{dq}_{\mathrm{r}} \%$ & $\mathrm{dc}_{\mathrm{r}} \%$ & $\mathrm{dVol}_{\mathrm{rmax}} *$ \\
\hline $\mathrm{H} 1$ & 5.9 & 66.9 & 9.6 & 7.2 & 61.6 & 9.1 \\
\hline $\mathrm{H} 2$ & 7.5 & 71.0 & 10.5 & 8.0 & 64.2 & 9.8 \\
\hline
\end{tabular}

* It is the maximum value of the indicator $d \operatorname{Vol}_{r}(\mathrm{t})$

Table 6. Indicators values for roughened floodplain

\begin{tabular}{|l|r|r|r|r|}
\hline \multirow{2}{*}{ Channel, hydrograph } & \multicolumn{2}{|c|}{ 1D Model } & \multicolumn{2}{|c|}{ 2D Model } \\
\cline { 2 - 5 } & $\mathrm{dq}_{\mathrm{r}} \%$ & $\mathrm{dc}_{\mathrm{r}} \%$ & $\mathrm{dq}_{\mathrm{r}} \%$ & $\mathrm{dc}_{\mathrm{r}} \%$ \\
\hline $\mathrm{A} 1, \mathrm{~T} 2$ & 3.7 & 9.0 & 2.6 & 6.6 \\
\hline B1, T100 & 3.0 & 7.3 & 1.8 & 6.7 \\
\hline Hogneau, February 2002 & 1.7 & 3.5 & 1.2 & 3.2 \\
\hline
\end{tabular}




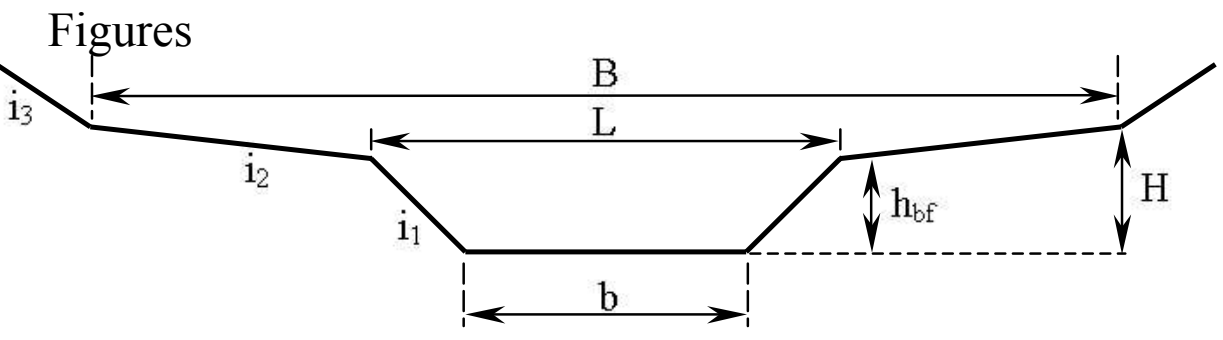

Fig.1. general cross section of a symmetrical compound channel

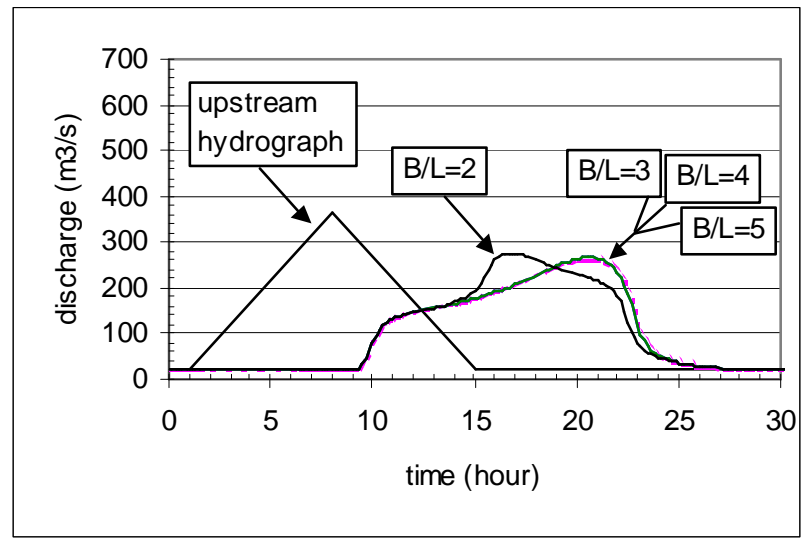

a) a modest flood

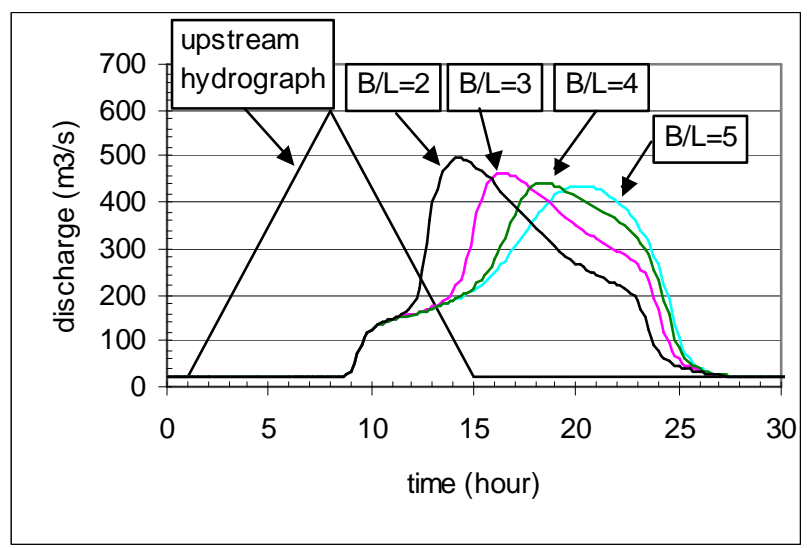

b) a higher flood

Fig.2. effect of the floodplain width on the propagated hydrograph in $\mathrm{Pk} 50$ $\left(L=50 \mathrm{~m}, S_{b f}=90 \mathrm{~m}^{2}, h_{b f}=2 \mathrm{~m}\right.$ and $\left.I=0.001, Q_{b f}=125 \mathrm{~m}^{3} / \mathrm{s}\right)$

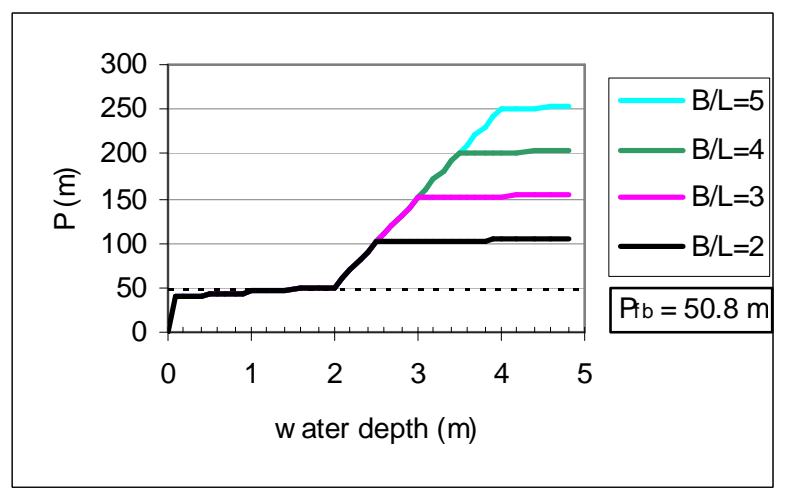

a) wetted perimeter $P$

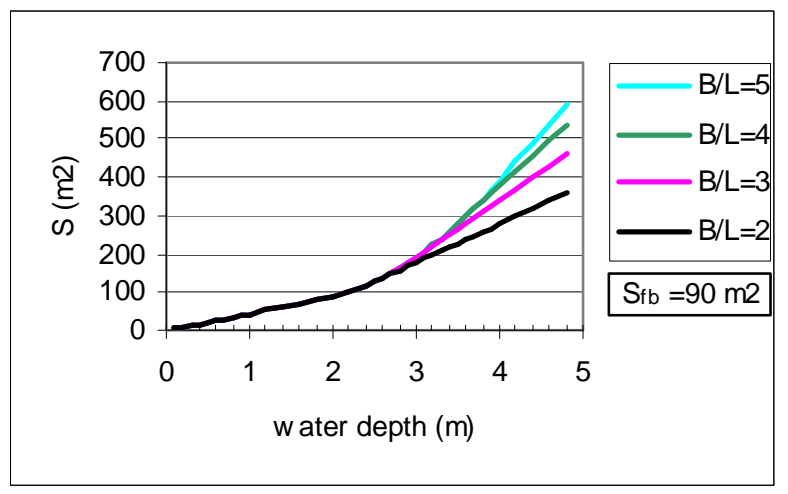

b) wetted area $S$

Fig.3. Variations of the wetted perimeter and the wetted area with the water depth for the test channels of Fig. 2 


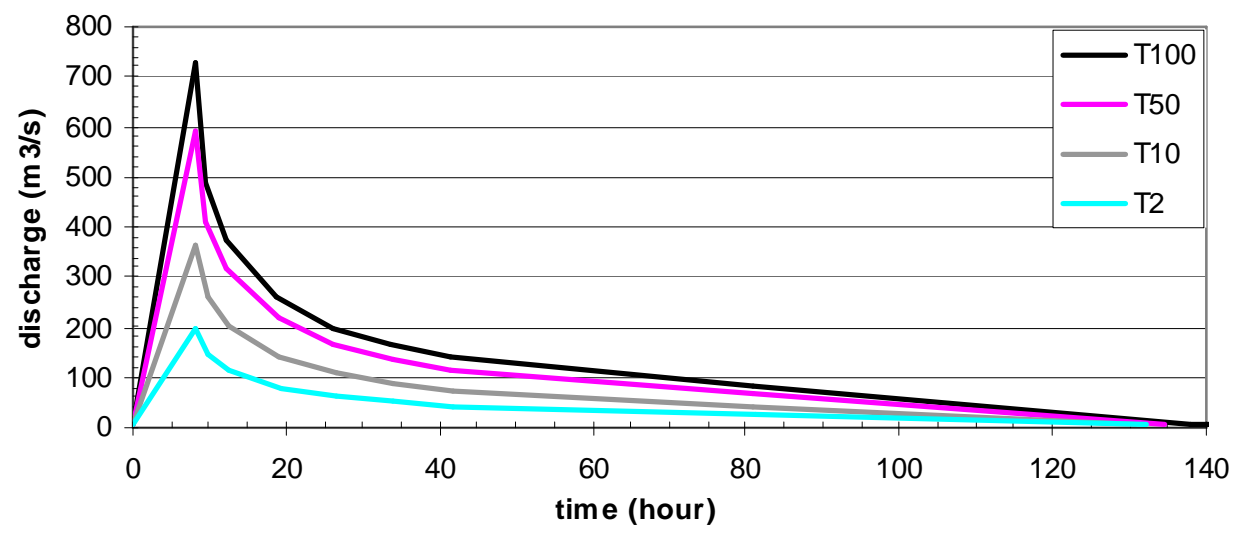

Fig.4. MFSH curves for a the $125 \mathrm{~km}^{2}$ basin, the Mimente river at Florac , used as input hydrographs (T100 indicates return period of 100 years)

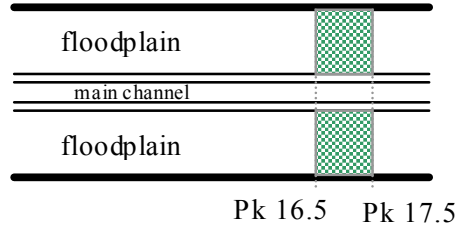

a) S1

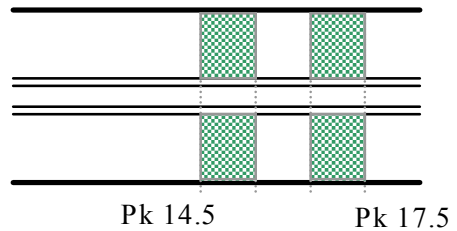

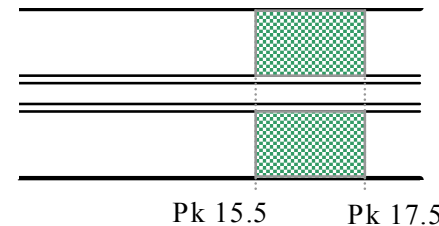

b) S2

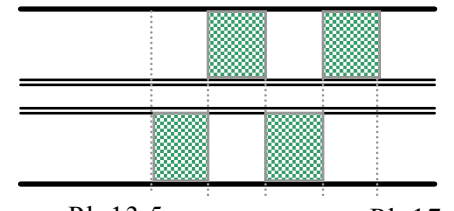

Pk 17.5

d) $\mathrm{S} 4$

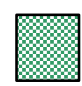

high roughness

$n=0.2$

c) $\mathrm{S} 3$

Fig.5. plan view of the channel; considered scenarios for RS

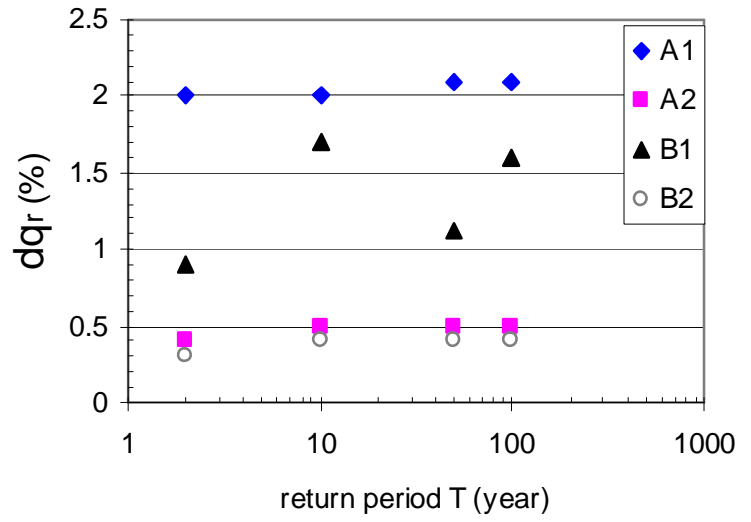

a) relative attenuations

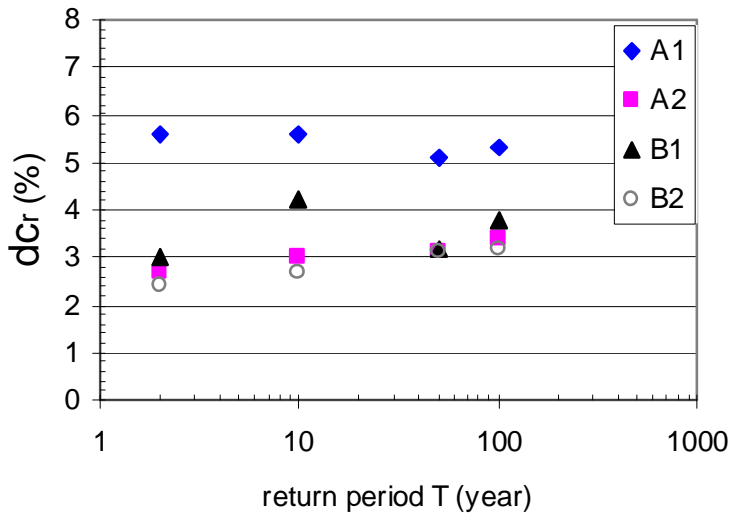

b) relative delays

Fig.6. 1D model results for the scenario S1 


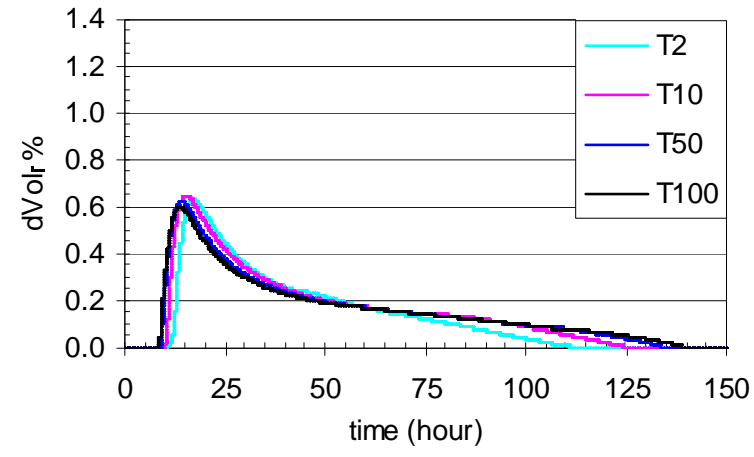

a) Channel $\mathrm{A} 1$ and the scenario $\mathrm{S} 1$

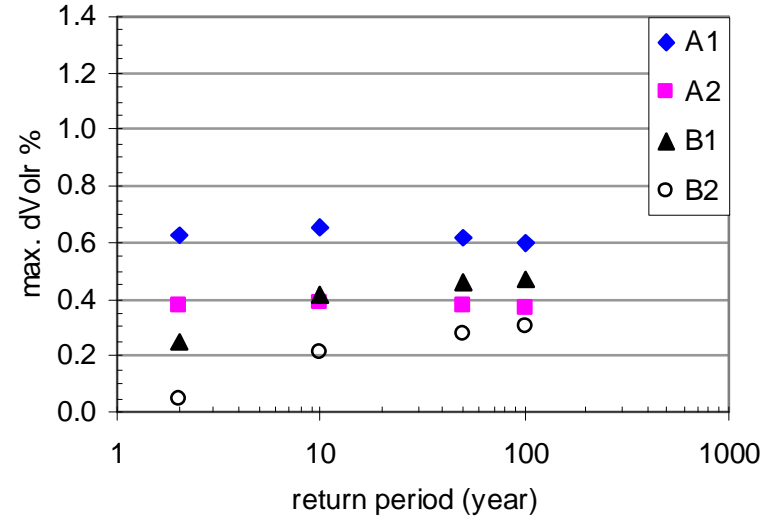

b) maximum values of $d \operatorname{Vol}_{r}(t)$

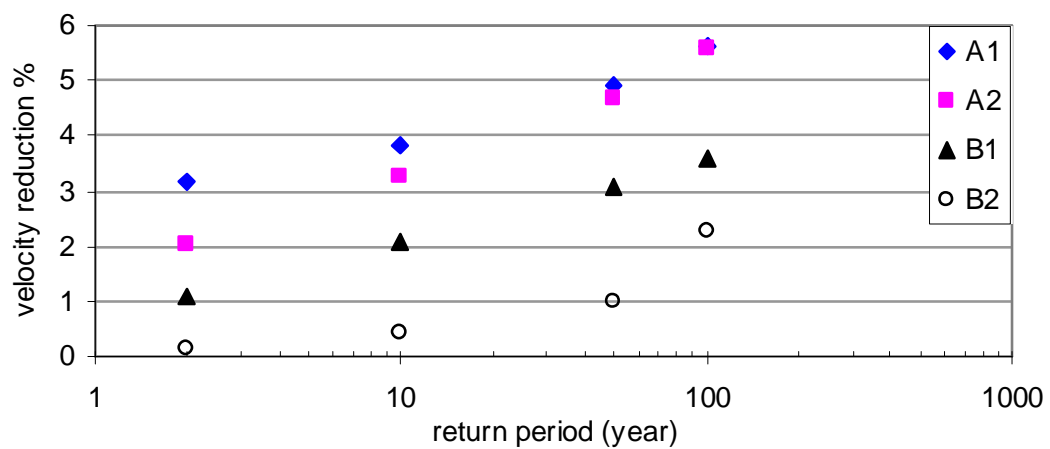

Fig.8. Velocity reduction in the axis of the channels in Pk16,5 ((S0 value - S1value)/S0 value) 


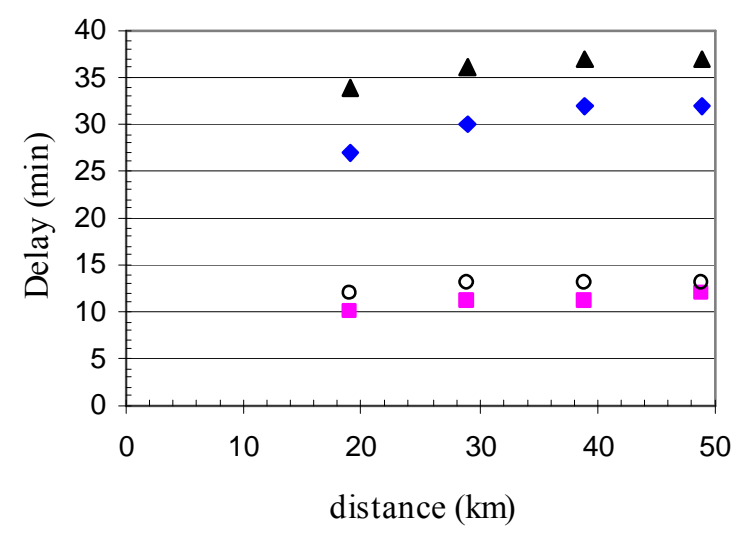

a) Peak delay of T10

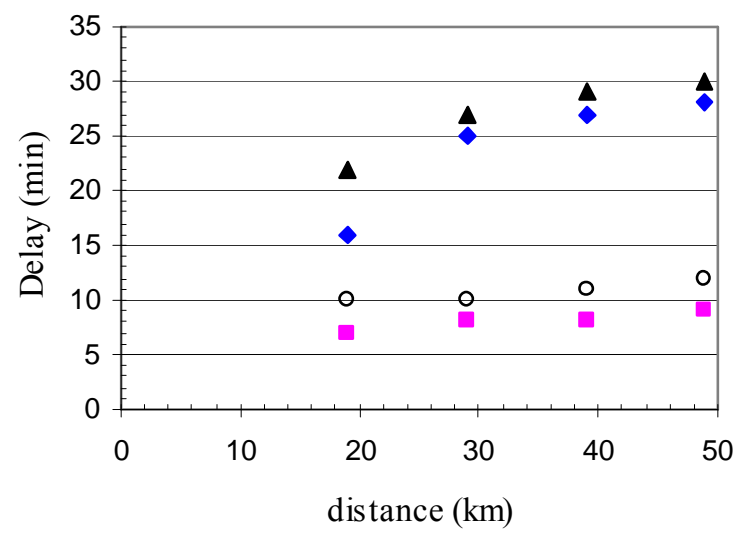

c) Peak delay of T100

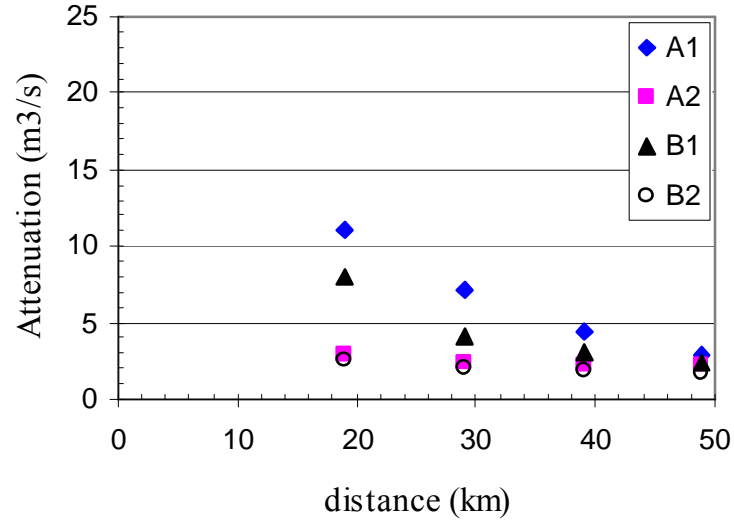

b) Peak attenuation of T10

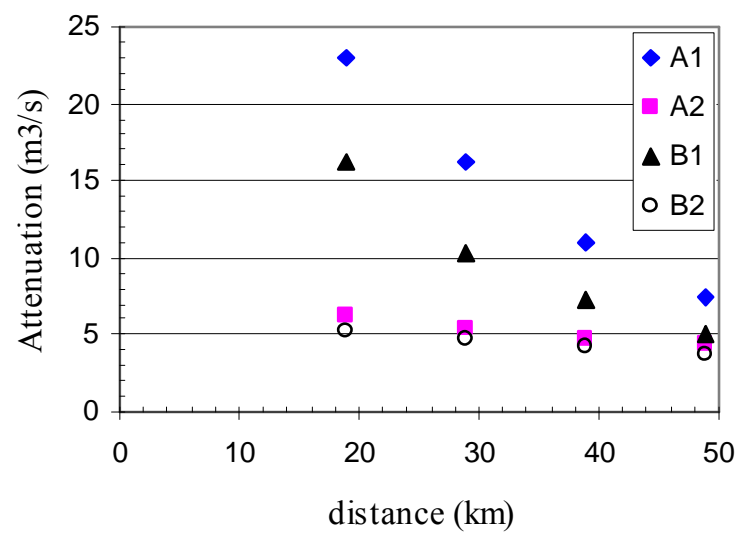

b) Peak attenuation of T100

Fig.9. Peak delay and attenuation variations far from the roughened strips (scenario S1)
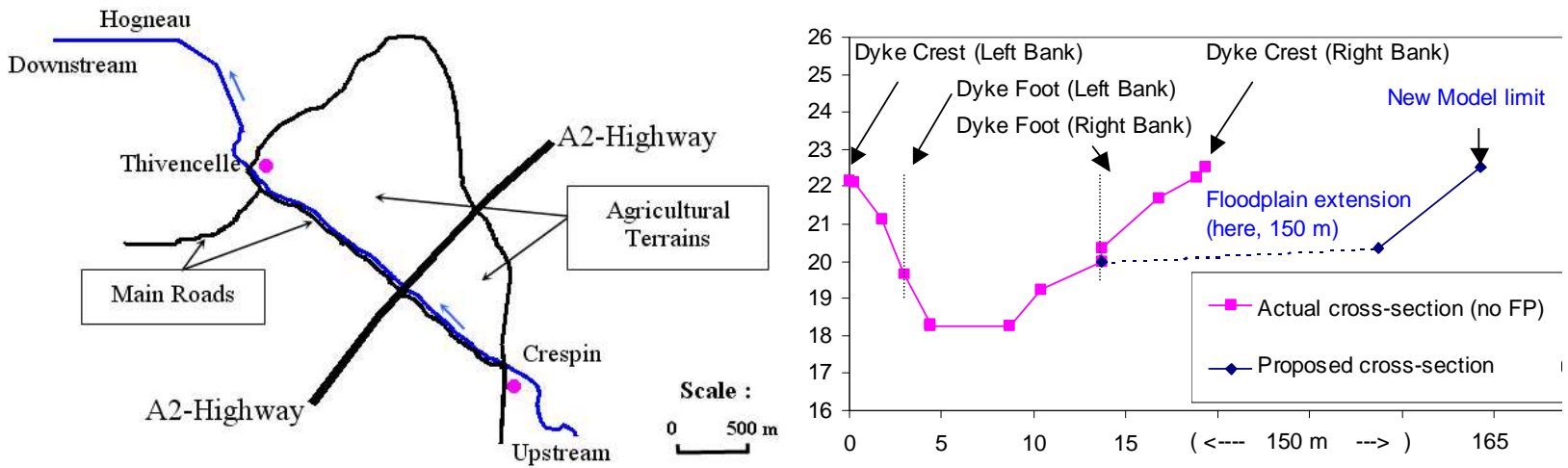

a) channel reach location

b) proposed cross-section enlargement (in $\mathrm{m}$ )

Fig.10. Hogneau river (a) map and (b) cross sections 


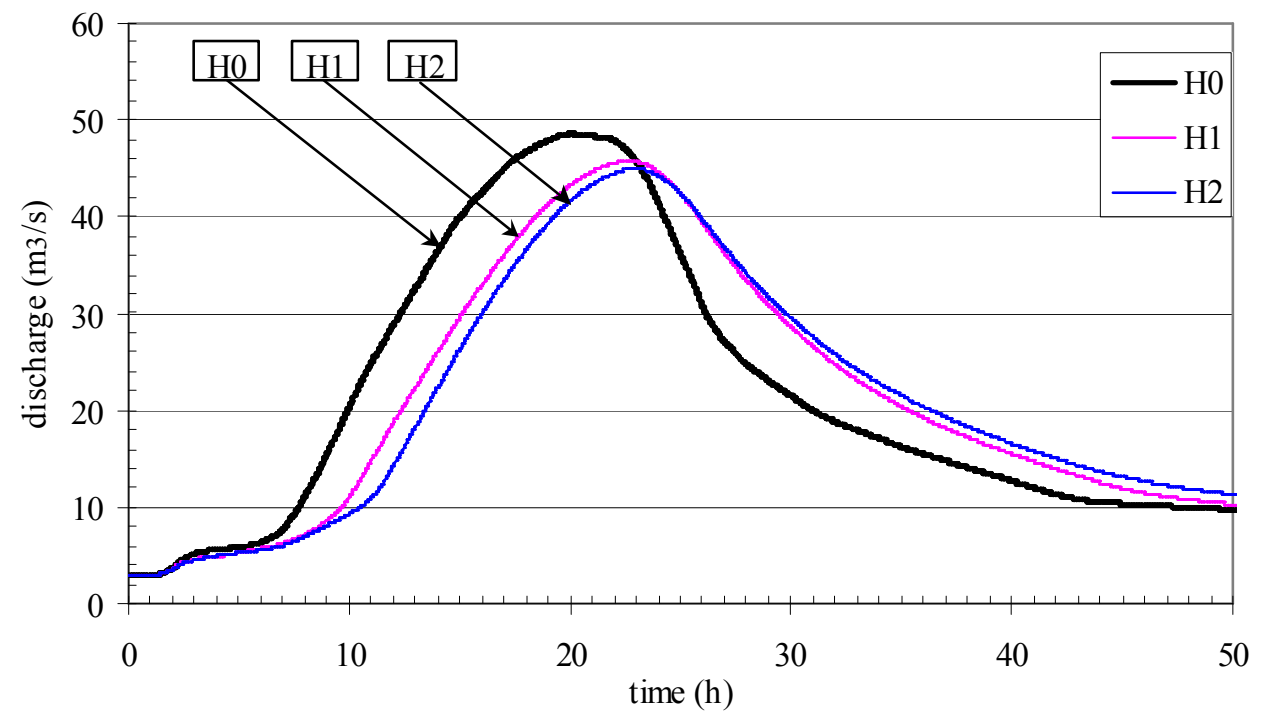

Fig.11. Routed hydrographs for different scenarios at Thivencelle 


\section{Appendix 1- Dimensional analysis of Saint-Venant equations}

The general one-dimensional form of Saint-Venant equations which express the flow in open channels is (Chow 1959):

Where:

$$
\begin{gathered}
\frac{\partial Q}{\partial x}+\frac{\partial S}{\partial t}+q=0 \\
\frac{\partial h}{\partial x}+\frac{\alpha u}{g} \frac{\partial u}{\partial x}+\frac{1}{g} \frac{\partial u}{\partial t}=I-I_{e}
\end{gathered}
$$

$Q$ is the discharge in $\mathrm{m}^{3} \mathrm{~s}^{-1}, q$ is the lateral flow per unit length in $\mathrm{m}^{2} \mathrm{~s}^{-1}, h$ is the depth in $\mathrm{m}, t$ is the time in second, $S$ is the wetted area of the section in $\mathrm{m}^{2}, u$ is the mean flow velocity in $\mathrm{ms}^{-1}, \alpha$ is the energy coefficient, $g$ is the acceleration of gravity in $\mathrm{ms}^{-2}, I$ is the slope of the channel bottom and $I_{e}$ is the energy gradient.

Let's define the reference parameters $t_{r}, l_{r}$ and $g_{r}$ as the reference time, length and gravity respectively. They are fixed parameters and may have some values to validate the following reference parameters for area, velocity, lateral flow per unit length and discharge:

$$
S_{r}=l_{r}^{2}, u_{r}=\frac{l_{r}}{t_{r}}, q_{r}=u_{r} l_{r}, Q_{r}=q_{r} l_{r}
$$

Then, dimensionless variables can be defined as:

$$
t_{*}=\frac{t}{t_{r}}, x_{*}=\frac{x}{l_{r}}, h_{*}=\frac{h}{l_{r}}, u_{*}=\frac{u}{u_{r}}, Q_{*}=\frac{Q}{Q_{r}}, S_{*}=\frac{S}{S_{r}}, g_{*}=\frac{g}{g_{r}}, q_{*}=\frac{q}{q_{r}}
$$

Where, the dimensionless variables and the reference parameters are indicated by the subscripts $*$ and $\mathrm{r}$ respectively.

To introduce the dimensionless variables of equation (1-4) to Saint-Venant equations, the following partial derivation forms may be applied:

$$
\frac{\partial}{\partial t}=\frac{1}{t_{r}} \frac{\partial}{\partial t_{*}}, \frac{\partial}{\partial x}=\frac{1}{l_{r}} \frac{\partial}{\partial x_{*}}
$$

Substituting the parameters of (1-1) and (1-2) by reference and dimensionless parameters of (1-4) and with some simplifications the following equations will be deduced:

$$
\begin{gathered}
\frac{\partial Q_{*}}{\partial x_{*}}+\frac{\partial S_{*}}{\partial t_{*}}+q_{*}=0 \\
\frac{\partial h_{*}}{\partial x_{*}}+\frac{\left(u_{r}\right)^{2}}{l_{r} g_{r}} \frac{\alpha u_{*}}{g_{*}} \frac{\partial u_{*}}{\partial x_{*}}+\frac{\left(u_{r}\right)^{2}}{l_{r} g_{r}} \frac{1}{g_{*}} \frac{\partial u_{*}}{\partial t_{*}}=I-I_{e}
\end{gathered}
$$

These are the dimensionless forms of Saint-Venant equations. 


\section{Appendix 2 - Debord formula}

Debord formula is presented in Nicollet and Uan (1979) paper and it is used by the model 1D, Mage5.

The Manning-Strickler equation gives the energy line gradient in uniform flow:

$$
\mathrm{I}_{\mathrm{e}}^{1 / 2}=\frac{\mathrm{Q}}{\mathrm{D}}
$$

Where: $Q$ is the discharge in $\mathrm{m}^{3} \mathrm{~s}^{-1}$ and $D$ is the conveyance $\left(D=k S R_{h}{ }^{2 / 3}: k\right.$ is Strickler roughness coefficient in $\mathrm{m}^{1 / 3} \mathrm{~s}^{-1}(k=1 / n), S$ is the wetted section area in $\mathrm{m}^{2}, R_{\mathrm{h}}$ is the hydraulic radius in $\mathrm{m}$ ).

Let's define the separate parameters for main channel and floodplain by Figure A2-1. Floodplain and main channel parameters are indicated by the subscripts ${ }_{M}$ and ${ }_{m}$ respectively.

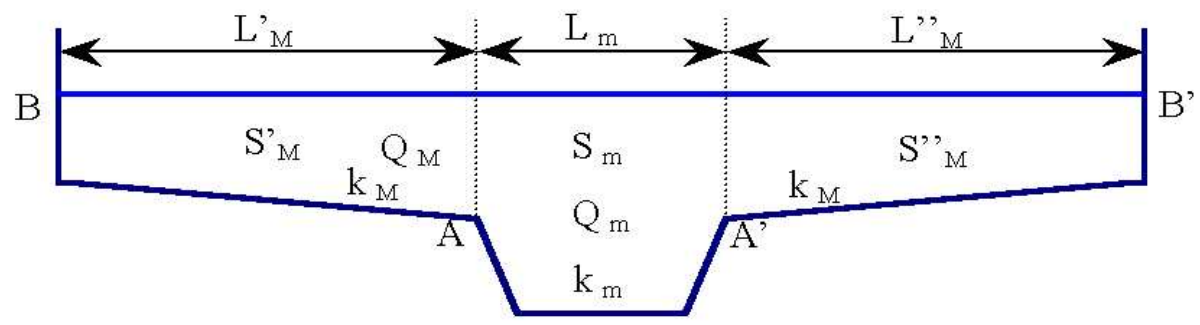

Figure A2-1: Compound channel parameter definition

Where: $Q=Q_{M}+Q_{m}, L=L{ }^{\prime}{ }_{M}+L_{m}+L{ }^{\prime \prime}{ }_{M}, L_{M}=L{ }_{M}+L{ }^{\prime}{ }_{M}, S=S_{m}+S_{M}, S_{M}=S^{\prime}{ }_{M}+S^{\prime}{ }_{M}$, $P=P_{m}+P_{M}, P_{M}=A B+A^{\prime} B^{\prime}, P_{m}=A A^{\prime}, R_{h}=S / P, R_{m}=S_{m} / P_{m}$ and $R_{M}=S_{M} / P_{M}$.

To apply the Manning-Strickler equation separately to main channel and floodplain of a compound channel section, the discharge should be distributed between the main channel and the floodplain. Indeed, the sub-discharge fractions should be determined. An experimental relation in steady state is found between main channel and floodplain discharges and roughness values based on data obtained from several compound channel physical model tests (Nicollet and Uan 1979). According to this experimental relation, we have:

$$
D=D_{m}+D_{M}=K_{m} A S_{m} R_{m}^{2 / 3}+K_{M} \sqrt{S_{M}^{2}+S_{m} S_{M}\left(1-A^{2}\right)} R_{M}^{2 / 3}
$$

where $A$ can be find by following equations:

$$
\left\{\begin{array}{l}
A=0.9\left(\frac{K_{m}}{K_{M}}\right)^{-1 / 6}=A_{0} \quad \text { if } \quad r=\frac{R_{M}}{R_{m}}>0.3 \\
A=\frac{1-A_{0}}{2} \cos \left(\frac{\pi r}{0.3}\right)+\frac{1+A_{0}}{2} \text { if } 0 \leq r \leq 0.3
\end{array}\right.
$$

and so:

$$
\eta=\frac{D_{m}}{D_{M}}=\frac{K_{m}}{K_{M}} \frac{A S_{m}}{\sqrt{S_{M}^{2}+S_{m} S_{M}\left(1-A^{2}\right)}} \frac{R_{m}^{2 / 3}}{R_{M}^{2 / 3}}
$$

Then the main channel and the floodplain interaction may be restored by the momentum (or Boussinesq) coefficient, $\beta$ :

$$
\beta=\frac{\int u^{2} d S}{V^{2} S} \Rightarrow \beta=\frac{\beta_{m} \frac{Q_{m}^{2}}{S_{m}}+\beta_{M} \frac{Q_{M}^{2}}{S_{M}}}{\frac{Q^{2}}{S}}
$$

where $u$ is the velocity in $\mathrm{ms}^{-1}$ and $V$ is the mean section velocity in $\mathrm{ms}^{-1}$. 
Supposing the momentum coefficient of each sub section equal to unity $\left(\beta_{m}=\beta_{M}=1\right)$, we have:

$$
\beta=\left(\frac{\eta^{2}}{S_{m}}+\frac{1}{S_{M}}\right) \frac{S}{(1+\eta)^{2}}
$$




\section{References}

Arcement, J. R., Schneider, V. R. 1989. Guide for Selecting Manning's Roughness Coefficients for Natural Channels and Floodplains, United States Geological Survey, Water-supply paper 2339, 67p.

Barnes, H. H., 1967. Roughness characteristics in natural channels. Washington DC, US Geological Survey.

Castro, J. M. Jackson, P. L., 2001. Bankfull discharge recurrence intervals and regional hydraulic geometry relationships: Patterns in the Pacific Northwest, USA. Journal of the American Water Resources Association. 37(5), 1249-1262.

Chow, V. T., ,1959, . ,Open-Channel Hydraulics, Mc-Graw-Hill, 680p.

Doyle, M. W., Boyd, K. F., et al., 1999. River restoration channel design: back to the basics of dominant discharge. Second International Conference on Natural Channel Systems., Niagara Falls, Canada, 14p.

Galéa G., Prudhomme C., 1994. The mono frequency synthetic hydrogramm (MFSH) concept: definition, interest and construction from regional QDF models built with threshold discharges, for little mountainous basins with rapid runoff. International conference, Alpine Regional Hydrology - A1: Regional synthesis of hydrological regimes (AMHY III), Stara Lesna, Slovakia, 12-16 September 1994, 9 p

Ghavasieh, A. R., Poulard, C., 2003. Hydrological regime variations assessment of Olivet by QdF method. Sixth International River Engineering Conference, Ahvaz-Iran, Shahid Chamran University, 12p.

Järvelä, J., 2002. Flow resistance of flexible and stiff vegetation: a flume study with natural plants. Journal of Hydrology. 269(1-2), 44-54.

Javelle, P., Ouarda, T., et al., 2002. Development of regional flood-duration-frequency curves based on the index-flood method. Journal of Hydrology. 258(1-4), 249-259.

Jayaratne, B. L., Tu, H., et al., 1995. Unsteady flow characteristics in compound channels with vegetated flood plains. Proc., 26th IAHR Congr., HYDRA 2000, London, 379384.

Knight, D. W., Brown, F. A., 2001. Resistance studies of overbank flow in rivers with sediment using the flood channel facility. Journal of Hydraulic Research. 39(3), 283301.

Kouwen, N., Fati-Moghadam, M., 2000. Friction factors for coniferous trees along rivers. Journal of Hydraulic Engineering. 126(10); pp 732-740.

LeVeque, R. J., 1990. Numerical Methods for Conservation Laws. Basel, Birkhauser Verlag; $214 \mathrm{p}$.

Mays, L. W., 1996. Water Resources Handbook. Arizona State University, McGraw-Hill; $1568 \mathrm{p}$.

Myers, W. R. C., Lyness, J. F., et al., 2000. Geometrical and roughness effects on compound channel resistance. Proceedings of the Institution of Civil Engineers-Water Maritime and Energy. 142(3), 157-166.

Moussa, R., 1996. Analytical Hayami solution for the diffusive wave flood routing problem with lateral inflow. Hydrological Processes. 10(9), 1209-1227.

Nicollet, G., Uan, M., 1979. Ecoulements permanents à surface libre en lits composés. La Houille Blanche $\mathrm{N}^{\circ} 1,21-30$.

Pang, B. D., 1998. River flood flow and its energy loss. Journal of Hydraulic EngineeringAsce. 124(2), 228-231.

Paquier, A., 1995. Modélisation et simulation de la propagation de l'onde de rupture de barrage (Modelling and simulating the propagation of dam-break wave). $\mathrm{PhD}$ Thesis, Université Jean Monnet de Saint Etienne, 215 pp. 
Paquier, A., 1998. 1-D and 2-D models for simulating dam-break waves and natural floods. In: M. Morris, J.-C. Galland and P. Balabanis (Editors), Concerted action on dam-break modelling, proceedings of the CADAM meeting, Wallingford, United Kingdom. European Commission, Science Research Development, Hydrological and hydrogeological risks., L2985, Luxembourg; 127-140.

Paquier, A., 2001. Rupture de barrage: validation des modèles numériques du Cemagref dans le cadre de CADAM (Dam-break wave: validating Cemagref's numerical models during CADAM). Ingénieries EAT, Décembre 2001(28), 11-21.

Phillips, J. D., 2002. Geomorphic impacts of flash flooding in a forested headwater basin. Journal of Hydrology. 269(3-4), 236-250.

Poulard, C., Oberlin, G., 2002. DIES IRAE: DIagnostic des Effets d'une Stratégie Intégrée de RAlentissement dynamique des Ecoulements, sur le régime des crues. Lyon, Cemagref report, 150p.

Prudhomme, C., Galéa, G., Mercier, G.X., 1997. Discharge-duration-Frequency model: an efficient synthetic model for the regionalisation of hydrological regimes. 17th annual American geophysical union: hydrology days, Fort Collins, USA, 14-18 April 1997, 375-386

Revel, L., Lamouroux, N., 2000. Typologie hydraulique des cours d'eau en liaison avec la qualité de l'habitat aquatique". Lyon, Cemagref report, 59p.

Versteeg, H. K., Malalasekera, W., 1995. An introduction to Computational Fluid Dynamics, Longman; 257p.

Wolff, C. G., Burges, S. J., 1994. An Analysis of the Influence of River Channel Properties on Flood Frequency. Journal of Hydrology. 153(1-4) 317-337.

Woltemade, C. J., Potter, K. W., 1994. A Watershed Modeling Analysis of Fluvial Geomorphologic Influences on Flood Peak Attenuation. Water Resources Research. 30(6), 1933-1942.

Yen, B. C., 2002. Open channel flow resistance. Journal of Hydraulic Engineering-ASCE. 128(1), 20-39. 